\title{
OXALIC ACID EXCRETION IN THE URINE OF CHILDREN *
}

\author{
JULIUS PARKER SEDGWICK \\ Professor of Pediatrics, University of Minnesota \\ MINNEAPOLIS
}

So far as I have been able to find, there are but two references in pediatric literature to the determination of the oxalic acid content of the urine of infants. The first is in the handbook of Pfaundler and Schlossmann ${ }^{1}$ published in 1906, and is as follows: "The studies of Sedgwick at the Heubner Clinic have shown us that children excrete absolutely larger amounts of oxalic acid than adults."

The second reference appeared last year in an article by Hans Aaron and Marianne Franz," on the "Organic Acids in the Urine of Infants." They state that, so far as they know, no examinations of infants' urines for oxalic acid appear in the literature. They mention records in the literature of the finding of 9 to $11 \mathrm{mg}$. of oxalic acid in the day's urine of a dog during the second week of starvation, and state that this must be endogenous oxalic acid. In addition to this, it is known that oxalic acid may be formed in the intestine as a byproduct of carbohydrate fermentation. From these facts and other studies on adults, it is generally accepted that there may be an endogenous formation of oxalic acid in the human metabolism, even on an oxalic acid free diet. It is also recognized, from examinations of the urine of rabbits, that a carbohydrate diet may increase the excretion of oxalic acid in the urine. This is supposed to be due to the imperfect oxidation of the glycuronic acid produced and a secondary formation of oxalic acid.

Hildebrandt ${ }^{3}$ gave rabbits that were being fed oats $30 \mathrm{gm}$. of glucose per day. These animals died with symptoms of acute intoxication. However, when he gave such animals lime with the same amount of sugar, they bore the diet without inconvenience. $\mathrm{He}$ explained this protective action of calcium by the supposition that the oxalic acid formed was bound by the calcium and rendered nontoxic. The work of Aron and Franz led to the following conclusions:

1. The urine of infants contains small amounts of oxalic acid almost without exception. It is found even when they are on oxalic acid free diets, such

* Submitted for publication Sept. 6, 1915.

1. Pfaundler and Schlossmann: Handbuch der Kinderheilkunde, 1906, ii, 522.

2. Aaron and Franz: Organic Acids in the Urine of Infants, Monatschr. f. Kinderh., 1914, xii, O., p. 645 .

3. Hildebrandt, H.: Ztschr. f. physiol. Chem., xxxv, 141. 
as breast milk or cow's milk and sugar, and this must be considered as either from the intestine, as a byproduct of carbohydrate fermentation or formed in the intermediary metabolism, that is, endogenous oxalic acid formation.

2. After feeding of cane sugar or dextrin-maltose preparations, the oxalic acid excretion was somewhat higher than on an exclusively milk diet. Starchy additions to the diet caused a definite increase in oxalic acid excretion.

3. No increase of the oxalic acid excretion could be demonstrated in cases of acute feeding disturbances.

\section{METHODS}

One reason that this subject has been so long neglected is that the methods of determination of oxalic acid in urine are so tedious and unsatisfactory.

This work was begun in 1905 at the suggestion of Professor Leo Langstein. The Autenrieth and Barth" method was used for the work done then. In this method the oxalic acid is thrown down as calcium oxalate; the oxalic acid is then isolated by heating with hydrochloric acid and dissolving in ether. An aqueous solution of the oxalic acid is finally obtained and reprecipitated with calcium chlorid. The precipitate is ignited and weighed as calcium oxid. The results were not published, as I found that the final precipitates contained phosphates.

The first part of the work presented here was done by the Salkowski method. In this method the urine is concentrated on the water-bath to one-third of its original volume, treated with concentrated hydrochloric acid, and the oxalic acid then dissolved in ether by shaking. As will be seen from the tables, this method gives lower results than the one devised by Albahary. ${ }^{5}$ This is largely due to the difficulty of extracting all of the oxalic acid by shaking with ether. Although Salkowski advises shaking four times with ether, I found that the seventh wash ether still contained oxalic acid, and Albahary quotes Luzatto as saying that the eighteenth extraction still contained oxalic acid.

The Albahary method consists in adding sodium carbonate to the urine, and concentrating it to one-third of the original volume over the water-bath. This alkalinization before heating has the advantage of preventing the volatilization as pointed out to us by Dr. Hall, or decomposition, of the oxalic acid which is so prone to occur when an acid solution of oxalic acid is heated. This concentrated solution is then treated with magnesium chlorid and ammonium chlorid and filtered to remove the phosphates. The filtrate is treated with calcitum chlorid and acetic acid. The precipitate is removed and ignited. The amount of oxalic acid is then reckoned from the calcium oxid obtained. This method is much shorter and control experiments with definite amounts of oxalic acid show that more, though not all, is recovered by this procedure.

As there are no reported results of oxalic acid determinations in the urine of the new-born, they are shown in Table 1 .

The results in Table 1 were obtained by the Salkowski method. The results shown in Table 2 were obtained by the Albahary method and are considerably higher.

If the results by the Salkowski method are averaged, we find a daily excretion of $2.75 \mathrm{mg}$., and by the Albahary method, $4.78 \mathrm{mg}$.

These were all normal breast fed new-born infants. The oxalic acid must therefore be endogenous. The quantities are distinctly larger than those found for older infants by Aaron and Franz.

Baby Ols. when 4 months old showed by the Salkowski method 7.19 and $4.77 \mathrm{mg}$. per day oxalic acid excretion.

4. Autenrieth and Barth: Ztschr. f. physiol. Chem., 1902, xxxv, 327.

5. Albahary, M.: Compt. rend. Acad. d. sc., 1903, cxxxvi, 1681. 
Harold R., 4 years old, with spasmophilia, gave a daily average by the Salkowski method from seventeen specimens, covering a period from October 31 to January 31, of $9.3 \mathrm{mg}$. Clifford Knick, 6 years old, with acute enteritis, enlarged tonsils, and adenoids, averaged $11.42 \mathrm{mg}$. for a period of eight days, also by Salkowski's method.

Violet Wall., aged 7 years, averaged by Salkowski's method, 10.53 for seven days during January. On January 10 , she excreted $20.44 \mathrm{mg}$. On January 20 she was etherized for a tonsillectomy and the next day she excreted $0.45 \mathrm{mg}$. only, coming back to 13.25 on the following day.

Table 1.-Oxalic Acid Determinations in the Urine of the New-Born

\begin{tabular}{|c|c|c|c|}
\hline Infant & Time Collected & $\begin{array}{l}\text { Quantity } \\
\text { c.c. }\end{array}$ & $\begin{array}{l}\text { Oxalic Acid } \\
\text { mg. }\end{array}$ \\
\hline 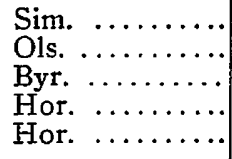 & $\begin{array}{l}\text { First four days after birth... } \\
\text { Second to fifth day after birth } \\
\text { First four days after birth... } \\
\text { Seventh day after birth...... } \\
\text { Eighth day after birth...... }\end{array}$ & $\begin{array}{l}146.5 \\
248.5 \\
140.0 \\
205.0 \\
265.0\end{array}$ & $\begin{array}{r}3.59 \\
4.94 \\
17.30 \\
9.43 \\
3.18\end{array}$ \\
\hline
\end{tabular}

TABLE 2.-Oxalic Acid Determinations by Albahary Method

\begin{tabular}{|c|c|c|c|}
\hline Infant & Time Collected or Age & $\begin{array}{l}\text { Quantity } \\
\text { c.c. }\end{array}$ & $\begin{array}{l}\text { Oxalic Acid } \\
\text { mg. }\end{array}$ \\
\hline 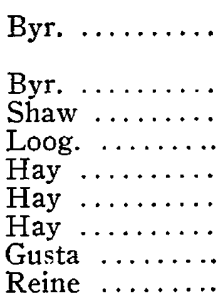 & 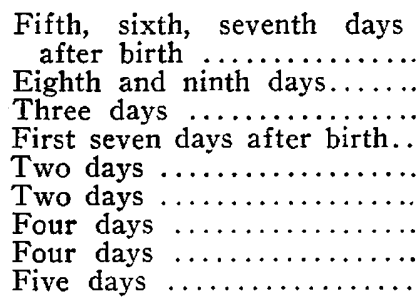 & $\begin{array}{r}307.0 \\
239.0 \\
168.0 \\
334.0 \\
89.0 \\
39.0 \\
34.0 \\
76.0 \\
123.0\end{array}$ & $\begin{array}{l}15.50 \\
11.23 \\
13.47 \\
12.35 \\
18.01 \\
12.35 \\
23.81 \\
24.48 \\
22.01\end{array}$ \\
\hline
\end{tabular}

Dorothy Rub., aged 6 years, with bronchitis and adenoids, showed an average of $9.9 \mathrm{mg}$. for six days by the Salkowski method. Hilding Berg., 11 years old, with chronic cardiac valvular disease and rheumatic fever, gave the low average of $3.04 \mathrm{mg}$. for four days by the Salkowski method, and on one of these days no oxalic acid could be demonstrated in the urine. In the older children, also, the results by the Albahary method were definitely higher. Doris Russel, 6 years old, showed an average daily excretion of $21.6 \mathrm{mg}$. for six days. D. Sten., 2 years old, with a healed pleurisy, by the Albahary method, for a preliminary period of fourteen days, on a general diet, gave a daily oxalic excretion of $21.77 \mathrm{mg}$. For the next four days on an oxalic acid free diet the daily excretion averaged $16.42 \mathrm{mg}$. The last day of this period she excreted $5.62 \mathrm{mg}$. only. During the following four days she was given $50 \mathrm{c.c}$. of rhubarb sauce daily and her oxalic acid excretion increased to an average of $32.85 \mathrm{mg}$. per day. The amount of oxalic acid in rhubarb is given by Neuberg ${ }^{6}$ as 2.4 gm. per kilogram of substance.

6. Neuberg, Carl: Von Noorden's Handbuch der Pathologie des Stoffwechsels, 1907, ii, 490 . 
SUMMARY

The older methods of determination of oxalic acid are tedious and imperfect. The Albahary method gives better results and is much more rapid.

New-born infants excrete oxalic acid in the urine in varying amounts up to $9 \mathrm{mg}$. per day.

Older children excrete oxalic acid in considerable quantity, and one child, fed on rhubarb, showed a definite increase in oxalic acid excretion during the period of rhubarb feeding.

If we accept the usual figures which are given for the oxalic acid excretion in adults, given by Neuberg as from 15 to $20 \mathrm{mg}$., the excretion in children is relatively and at times absolutely higher. 